\title{
Reproducible polyarthritis in rats caused by Mycoplasma arthritidis
}

\author{
P. C. T. HANNAN* AND B. O. HUGHES \\ From the Medicinal Research Centre, Beecham Research Laboratories, The Pinnacles, Fourth Avenue, Harlow, \\ Essex
}

Polyarthritis of rats was first described by Collier (1938), who observed spontaneous polyarthritis in a wild rat whilst working in Java. Findlay, Mackenzie, MacCallum, and Klieneberger (1939) described a similar disease in laboratory rats in London and were able to demonstrate that it was caused by a species of mycoplasma which they provisionally termed L7. Klieneberger (1939), Preston (1942), Tripi and Kuzell (1947), Parkes and Wrigley (1951), Ward and Jones (1962), Cole, Miller, and Ward (1967), and Schütze (1968) have all demonstrated the arthritogenic properties of Mycoplasma arthritidis in rats. The adaptation of this disease in rats as an animal model for the purpose of evaluating either antiathritic or antimycoplasma agents has been examined by Tripi and Kuzell (1947), Preston (1942), and Schütze (1968). The difficulty in maintaining the virulence of these organisms and creating a reproducible polyarthritis in rats has been reported by Jasmin (1967) and Schütze (1968).

Although Tripi and Kuzell (1947) described a method whereby the virulence of the mycoplasma is maintained by frequent in vitro and in vivo passage, most workers have worked either with cultures freshly isolated from naturally occurring infections or with tumour exudates containing the mycoplasma (Jasmin, 1957), or have used adjuvants to enhance the virulence of their strains. Recently Cole and others (1967) have been consistently able to produce polyarthritis with stock cultures of $M$. arthritidis but only with high inocula obtained by concentrating their cultures by centrifugation.

During the past 18 months we have developed a method which causes 100 per cent. incidence of polyarthritis in rats using unconcentrated cultures of $M$. arthritidis. The virulence of this strain has been maintained for over one year at $-20^{\circ} \mathrm{C}$. During the development of the method a number of strains of Mycoplasma arthritidis were tested for their arthritogenic properties in rats. This report gives details of the methods, mycoplasma strains, and of the $\omega$ disease produced by Mycoplasma arthritidis ATCC $\dot{\omega}$ No. 14124.

\section{Material and methods}

(1) SOURCE OF MYCOPLASMA STRAINS Four strains of Mycoplasma arthritidis were used in these experiments. Strain PG6 was obtained from Dr. $\vec{\varphi}$ D. Taylor-Robinson, ${ }^{1}$ in the form of an arginine broth culture and has been designated M. arthritidis PG6 (T-R). Strains H606 (ATCC 13988), PG6 (ATCC 19611), and Jasmin (ATCC 14124) were all obtained freeze-dried from American Type Culture Collection.2

(2) MEDIA

The basal media for the growth of these strains consisted of heart infusion broth (Difco) 70 per cent. $v / v$, horse $\bar{O}$ serum No. 3 (Wellcome Reagents Ltd. $^{3}$ ) 20 per cent. $\mathrm{v} / \mathrm{v}$, fresh yeast extract 10 per cent. v/v. Thallium acetate and penicillin $G$ were added to the medium to give? concentrations of 0.025 per cent. and 200 units per ml. respectively. The thallium acetate was omitted from the $\bar{\alpha}$ medium when cultures were used directly for animal $\frac{0}{3}$ inoculation. When solid medium was required, Bacto Agar (Difco) was added to the heart infusion broth to a $\delta$ concentration of 1.4 per cent. before sterilization. Broth and agar were sterilized by autoclaving at $15 \mathrm{lb}$. pressure $ᄋ$ for $15 \mathrm{~min}$.

Media for carbohydrate fermentation tests consisted of $\frac{D}{O}$ the basal medium with the addition of $0 \cdot 25-1 \cdot 0$ per cent. of the following carbohydrates: glucose, sucrose, lactose, $N$ maltose, xylose, rhamnose, dulcitol, galactose, mannitol, and salicin plus 0.002 per cent. w/v phenol red. Meta- 0 bolism of arginine was observed using the basal medium containing 1 per cent. $\mathrm{w} / \mathrm{v}$ arginine monohydrochloride $\sigma$ and 0.002 per cent. phenol red (Taylor-Robinson, 1967), definite change from orange to pink denoting breakdown of the amino acid with production of ammonia.

'Dr. D. Taylor-Robinson, Northwick Park Hospital, Harrow, $T$ Middlesex

-American Type Culture Collection 12301, Park Lawn Drive, Rock-

ville, Maryland, 20852, U.S.A. Wellcome Research Laboratories,

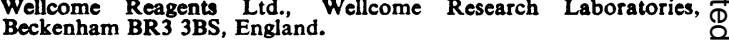


Lipolytic activity was tested by the method described by Fabricant and Freundt (1967) on basal agar containing 10 per cent. egg yolk suspension (oxoid). Reduction of 2, 3, 5-triphenyl-2H-tetrazolium chloride (TTC) was tested in sloppy agar according to the method of Fabricant and Freundt (1967) incorporating 0.2 instead of 0.005 per cent. TTC.

Haemolysis and haemadsorption tests were carried out by the method of Manchee and Taylor-Robinson (1968), using 3 per cent. erythrocytes of the horse, sheep, guinea-pig, and rabbit incorporated in basal agar and 3 per cent. erythrocytes in phosphate buffered saline at pH $7 \cdot 2$ respectively.

Growth inhibition tests were carried out on basal agar by the method described by Clyde (1963), using oxoid AA discs impregnated with antisera obtained from Microbiological Associates U.S.A."

(3) ESTABLISHMENT AND STORAGE OF

CHALLENGE CULTURES

In order to reduce the chance of losing any existing virulence present in the strain by repeated subculture in vitro, each strain was grown in broth or on agar a minimum number of times before storage and animal inoculation. Strain PG6 (T-R) was cloned twice before freeze-drying and storage, while the ATCC strains were not cloned. Freeze-dried stocks of each strain were prepared from 72-hr broth cultures by adding an equal volume of sterile skimmed milk to the culture and freezedrying $0 \cdot 1-0.2 \mathrm{ml}$. volumes.

Standard inocula were prepared in the following manner. The contents of one freeze-dried ampoule were re-suspended in $5 \mathrm{ml}$. broth medium and incubated at $37^{\circ} \mathrm{C}$. for $72 \mathrm{hrs} .1 \mathrm{ml}$. of this culture was then used to inoculate $100 \mathrm{ml}$. of broth, which was again incubated at $37^{\circ} \mathrm{C}$. for $72 \mathrm{hrs}$ before dispensing $1 \mathrm{ml}$. aliquots in sterile vials and storing at $-20^{\circ} \mathrm{C}$.

These frozen $1 \mathrm{ml}$. aliquots of mycoplasma culture were the standard inocula used to seed cultures in future experiments.

(4) STABILITY OF FROZEN INOCULA

Viability checks carried out on the frozen inocula by the Miles and Misra (1938) method have shown that the viability of cultures stored in this way has remained stable for a period of 15 months (Table $I$ ) and that, when used to seed a standard volume of broth, consistent numbers of mycoplasma are present after a standard period of incubation (Table II).

'Microbiological Associates Inc., 4733 Bethesda Avenue, Bethesda, Maryland 20014, U.S.A.

Table I Viable counts of Mycoplasma arthritidis strains stored at $-20^{\circ} \mathrm{C}$. for 15 months

\begin{tabular}{|c|c|c|}
\hline Date & $P G 6(T-R)$ & PG 6 (ATCC 19611) \\
\hline $\begin{array}{l}\text { Sept., } 1968 \text { (Pre-frozen) } \\
\text { Sept., } 1968 \text { (Frozen) } \\
\text { Sept., } 1969 \text { (Frozen) } \\
\text { Nov., } 1969 \text { (Frozen) }\end{array}$ & $\begin{array}{l}5 \cdot 3 \times 10^{4} \\
6 \cdot 3 \times 10^{3} \\
4 \cdot 0 \times 10^{4} \\
8 \cdot 5 \times 10^{4}\end{array}$ & $\begin{array}{l}2.1 \times 10^{6} \\
1.5 \times 10^{6} \\
9.5 \times 10^{7} \\
7.5 \times 10^{7}\end{array}$ \\
\hline
\end{tabular}

Note: The viable counts have been performod on singlo samples of the culture prepared, distributod, and frozen in September 1968 and maintained at $-20^{\circ} \mathrm{C}$. Counts were performed purely a checks of the viability of the organism before experiments and duplicates were not carried out.
Table II Viable counts on 48-hr broth cultures of Mycoplasma arthritidis (Jasmin-ATCC 14124)

\begin{tabular}{|c|c|c|}
\hline Sample & Date & Count (CFU/ml.) \\
\hline $\mathbf{A}$ & $\begin{array}{l}2 / 12 / 68 \\
12 / 12 / 68 \\
20 / 12 / 68 \\
26 / 1 / 69\end{array}$ & $\begin{array}{l}3.4 \times 10^{8} \\
4.2 \times 10^{8} \\
3.3 \times 10^{8} \\
5.0 \times 10^{8}\end{array}$ \\
\hline B & $\begin{array}{r}14 / 1 / 69 \\
28 / 2 / 69 \\
17 / 4 / 69 \\
18 / 4 / 69 \\
6 / 6 / 69 \\
10 / 6 / 69\end{array}$ & $\begin{array}{l}8.5 \times 10^{9} \\
2.3 \times 10^{8} \\
3.9 \times 10^{8} \\
1.2 \times 10^{7} \\
9.0 \times 10^{8} \\
5.0 \times 10^{8}\end{array}$ \\
\hline $\mathbf{C}$ & $\begin{array}{r}3 / 3 / 69 \\
18 / 7 / 69 \\
21 / 7 / 69 \\
28 / 7 / 69\end{array}$ & $\begin{array}{l}2.6 \times 10^{8} \\
4.2 \times 10^{8} \\
2.6 \times 10^{8} \\
2.6 \times 10^{8}\end{array}$ \\
\hline
\end{tabular}

Samples A, B, and C were subcultures from a common stock derived after two passages from ATCC 14124, dispensed in $1 \mathrm{ml}$. aliquots and frozen at $-20^{\circ} \mathrm{C}$.

53-hr culture.

Growth curves carried out on each strain showed that when one frozen vial was used to seed $100 \mathrm{ml}$. of broth medium the number of viable cells generally reached a peak between 48 and $53 \mathrm{hrs}$ after incubation at $37^{\circ} \mathrm{C}$. (Fig. 1, overleaf).

A period of $48 \mathrm{hrs}$ was therefore selected as the standard period of incubation for all challenge cultures before injection.

\section{Initial screening of four strains of $\boldsymbol{M}$. arthritidis}

Each of the above strains of Mycoplasma arthritidis was screened for its virulence in terms of producing polyarthritis in rats. Groups of eight female SpragueDawley Specific Pathogen Free rats (Charles Rivers France ${ }^{5}$ ) weighing between 150 and $170 \mathrm{~g}$. were injected by one of the following routes and observed daily for a period of one month for signs of disease:

(1) Intravenously with $0.5 \mathrm{ml} . / 100 \mathrm{~g}$. body weight of broth culture.

(2) Intraperitoneally with $2 \mathrm{ml}$. broth culture.

(3) Into the plantar surface of the foot pad of the right hind foot with $0.1 \mathrm{ml}$. of a culture of Mycoplasma arthritidis containing $\mathbf{0 . 2}$ per cent. sterile agar.

With $M$. arthritidis strain ATCC 14124 polyarthritis devloped after 3 days in all rats injected by the intravenous route. One rat injected intraperitoneally developed severe arthritis on the left fore paw. No arthritis developed after foot-pad injection. Arthritis was not caused by any of the other $M$. arthritidis strains, but each strain (including ATCC 14124) caused an abcess to develop at the site of the foot-pad injection. This eventually burst and healed spontaneously.

Charles Rivers France, Siège Social et Centre d'Élebage, SaintAubin-les-Elbeuf, Boite Postale 29, Seine-Maritime, France 


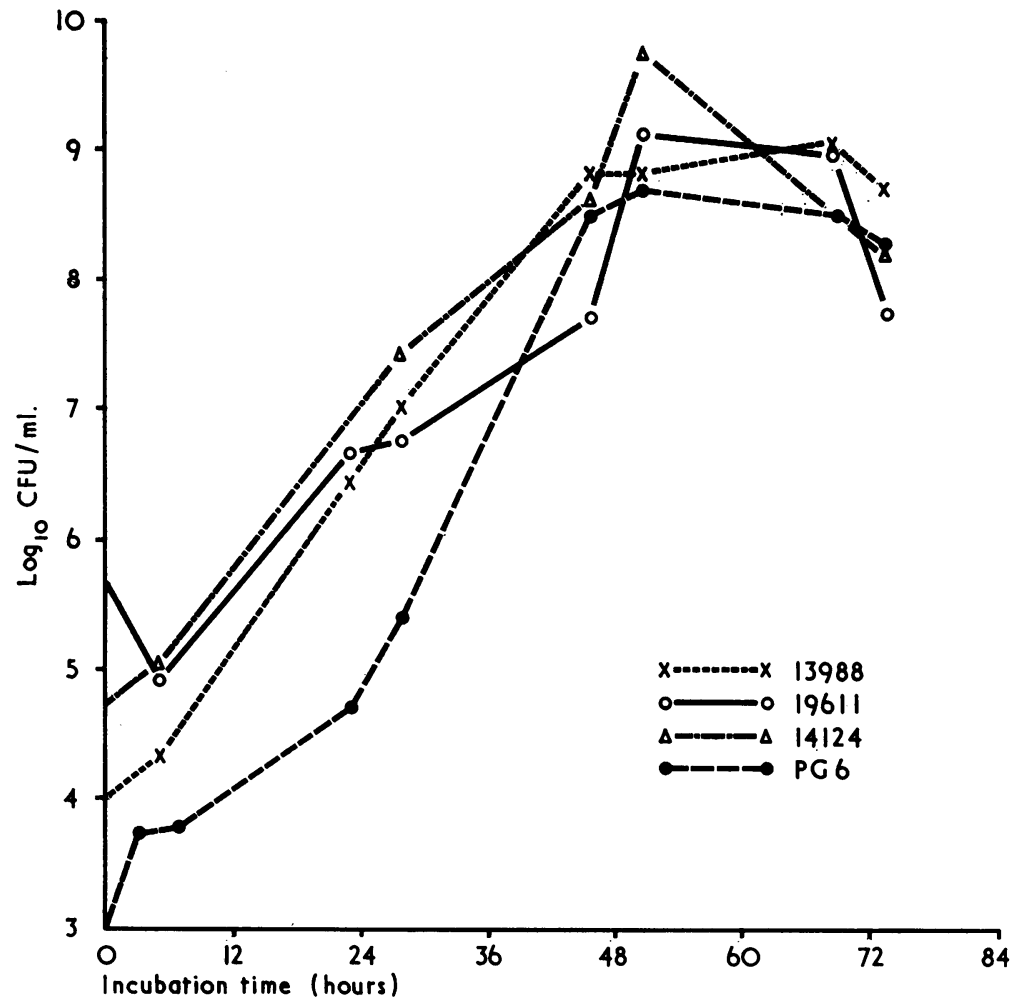

FIG. 1 Growth curves of four strains of $\mathbf{M}$. arthritidis

Studies using $M$. arthritidis ATCC 14124

Experiments carried out over the past 15 months using ATCC No. 14124 intravenously in rats have shown the infection to be highly reproducible. The $\mathrm{ID}_{50}{ }^{6}$ of this strain is approximately $1 \times 10^{7}$ colonyforming units (CFU). Symptoms of the disease begin to appear 2 to 3 days after intravenous injection. The first signs are those of pilo erection, obvious pain in the limbs as judged by the uncomfortable manner in which the animals walk, and their tendency to lie on the floor of the cage with their feet off the ground. The animals lose weight, look ill, appear hunched, and are sensitive to handling, often squeaking when touched. After the initial response the hind legs become inflamed and may swell either at the tarsus or along the foot. Either or both of the fore paws may swell at the carpus and at some of the smaller peripheral joints (Fig. 2). The disease process extends over a period of approximately 4 weeks reaching a peak 7 to 8 days after injection (Fig. 3). After this time the swellings gradually subside and at 4 weeks have usually disappeared. The animals are resistant to subsequent re-infection with the challenge organism. In addition to the arthritis, paralysis of the hind limbs, opacity of the eye, and slight bleeding from the nose have all been recorded in infected rats.

'ID.. = the number of oreanisms required to infect 50 per cent. of the animals.
Mycoplasma are easily isolated from affected $\stackrel{2}{\mathbb{D}}$ joints in broth and on agar containing thallium $\overrightarrow{\vec{B}}$ acetate and penicillin $G$ and cause polyarthritis $\exists$ when re-injected into rats. Tests for identification of these isolates have shown them to be indistinguishable from the challenge culture. Both isolates and challenge organisms grow best in an atmosphere of $?$ 95 per cent. $\mathrm{N}_{2}+5$ per cent. $\mathrm{CO}_{2}$ and show the characteristic 'fried egg' appearance on agar. Both cultures metabolize arginine but do not ferment any of the carbohydrates listed above. Neither show lipolysis nor haemadsorption of horse, sheep, 은 guinea-pig, or rabbit erythrocytes. Both show $\beta$ 긍 haemolysis of guinea-pig erythrocytes after $48 \mathrm{hrs}$ when incubated aerobically and slight haemolysis $N$ of sheep and rabbit erythrocytes. Both cultures are inhibited by $M$. arthritidis (CAMPO) PG 27 antiserum but not by antisera to $M$. hominis (PG 21), $M$. pneumoniae, $M$. pulmonis (Negroni Agent), $M$. hyorhinis (GDL), M. fermentans (PG 18), M. salivarium (PG 20), $M$. orale type I (pharyngis- $\mathrm{CH}-\Phi_{\mathbb{D}}$ 19299), M. orale type II (CH-20247), and M. laid-? lawii A (PG 8). Neither reduces TTC.

\section{Assessment of the disease}

This was made both by recording the change in mean body weight which occurs in infected rats and byo응 

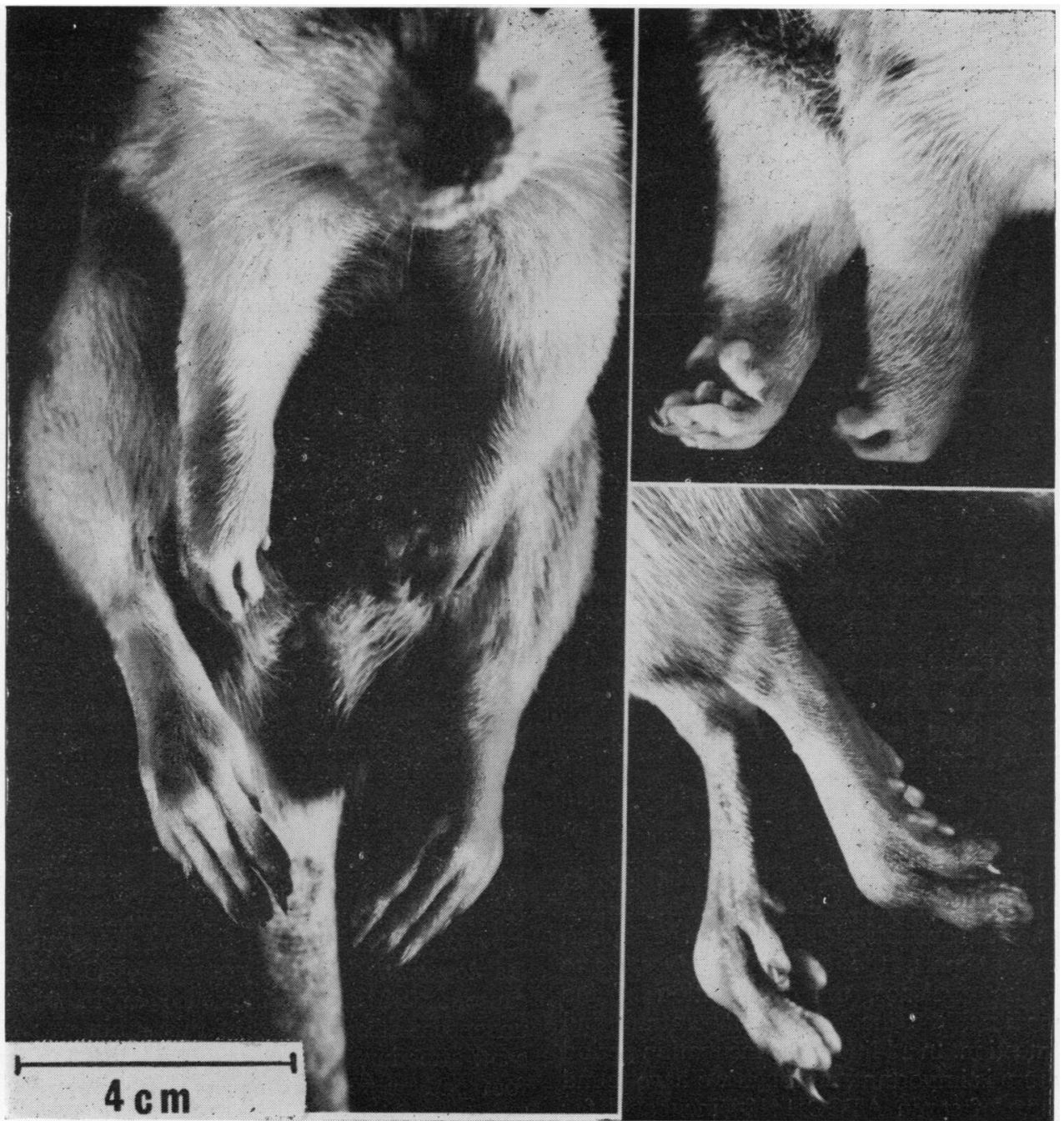

FIG. 2 Appearance of rats' feet.

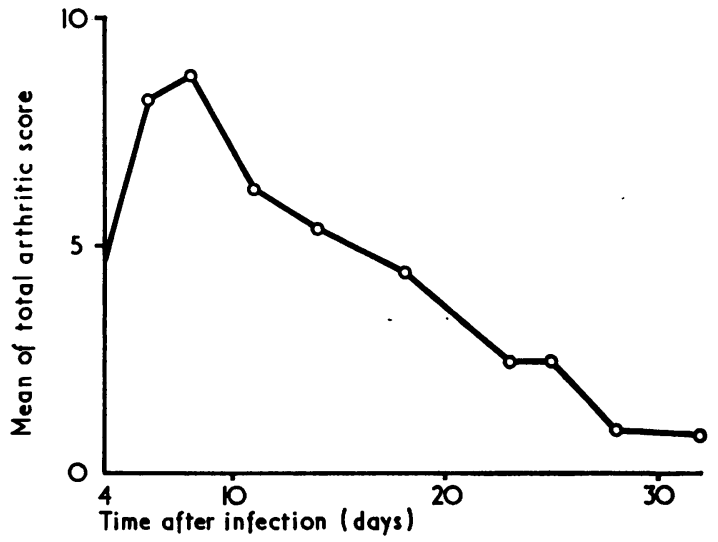

F1G. 3 Arthritis caused in rats by strain ATCC 14124. 'scoring' the arthritis which develops. Both methods have been found closely to reflect the visible course of the infection.

(i) Mean weight change

Maximum weight loss usually cccurs between days 7 and 9 after infection. This corresponds to the time when the arthritis is visibly at its peak. After this the weight increases as the animals recover (Fig. 4, overleaf).

(ii) Mean arthritic score

A score of 1 to 5 was allotted to each swollen carpus or tarsus depending on the severity, five denoting the most severe reaction. In addition a score of 1 was given to each peripheral joint involved (metacarpophalangeal, metatarsophalangeal, interphalangeal). By summing these scores for each rat and then taking 


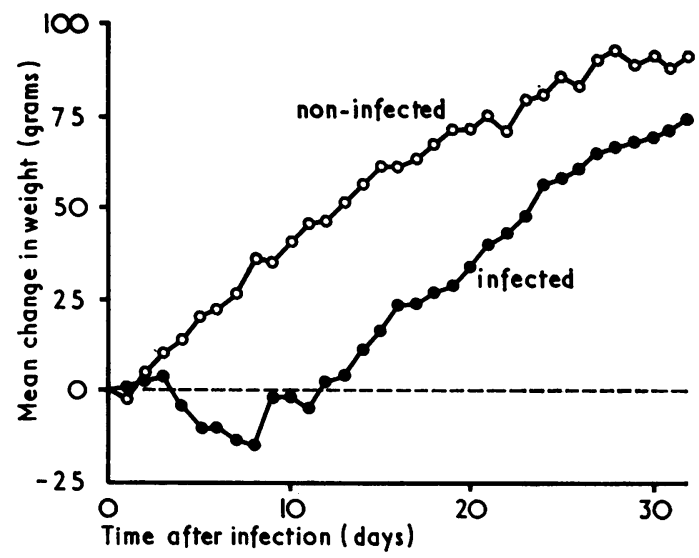

FIG. 4 Effect of mycoplasmal arthritis on growth of developing rats.

the group mean, the mean arthritic score was determined. The maximum possible score for a rat by this method is 76 , although a score of this magnitude has yet to be observed. The mean score at the time of peak activity is of the order of 10 but diminishes daily after this time and by the end of 3 weeks has usually returned to nil.

\section{Discussion}

Success in creating a reproducible polyarthritis in rats will, in addition to the diet and environmental conditions of the animals, depend on the strain and sex of the animals, the strain of Mycoplasma arthritidis, its virulence, the composition of the culture medium, the incubation temperature, and route of infection. In addition, the incubation period of the culture is important, although we have found that cultures of strain ATCC 14124 incubated for periods of from 24 to 77 hrs will cause arthritis in 100 per cent. of the rats injected. With 48-hr cultures of this strain this has amounted to a total of 592 rats developing polyarthritis after intravenous infection. At present it is difficult to understand why in these laboratories strain ATCC 14124 will so easily cause arthritis, whereas in the laboratories of Cole and others (1967), Schütze (1968) and GolightlyRowland, Cole, Ward, and Wiley (1970) difficulty has been encountered in creating arthritis regularly with unconcentrated cultures of this organism. It is particularly interesting since Schütze used rats of the same strain and weight range with media and incubation times similar to ours. The difference between these results and those reported by Cole and others (1967) could possibly be explained by the difference in susceptibility of the Holtsman rat strain used in their experiments.

The fact that strain ATCC 14124 (isolated by Dr. Klieneberger-Nobel from rat cancer tissue obtained from Dr. G. Jasmin, Montreal, Canada) has been maintained in vitro in laboratories since before 1959 and is still found to be active, would indicate that virulence of Mycoplasma arthritidis is not lost on subculture and storage as easily as has been supposed by Jasmin (1967) and Schütze (1968), and that under optimal conditions the organism will cause arthritis in rats. Care should be taken that unnecessary passages in vitro are not carried out with strains required for experimentation in vivo. The system of preparing standard inocula with a minimum number of passages in vitro before storage at $-20^{\circ} \mathrm{C}$. has proved effective in these laboratories and is probably responsible, at least in part, for the reproducible results achieved. The reproducibility of this disease in rats offers an animal model which could be used both to evaluate chemotherapeutic drugs and to study mycoplasmal arthritis.

\section{Summary}

Mycoplasma arthritidis strains PG 6(T-R), ATCC 19611, ATCC 13988, and ATCC 14124, were each screened for their arthritogenic virulence in SpragueDawley female rats. Only strain ATCC 14124 would cause arthritis. The incidence of infection with unconcentrated cultures of this strain was 100 per cent. after intravenous injection. Injection into the foot pad or pertitoneum was generally ineffective. The incubation time of the culture was not critical above $24 \mathrm{hrs}$, cultures from 24 to $77 \mathrm{hrs}$ all causing arthritis in 100 per cent. of the infected rats.

Details of the storage, culture, and identification of the mycoplasma strains are given.

The animal model is considered to be suitable for the chemotherapeutic evaluation of drugs and the study of mycoplasmal arthritis.

The authors wish to thank Miss P. E. Marlow for technical assistance, Dr. D. Taylor-Robinson for the sample of culture PG 6, and Mr. D. F. Lawson for the photographs.

\section{References}

CLYDE, W. A., JR. (1964) J. Immunol., 92, 958 (Mycoplasma species identification based upon growth inhibition by specific antisera).

Cole, B. C., Miller, M. L., AND Ward, J. R. (1967) Proc. Soc. exp. Biol. (N.Y.), 124, 103 (A comparative study on the virulence of Mycoplasma arthritidis and 'Mycoplasma hominis Type 2' strains in rats).

CollIBR, W. A. (1938) Geneesk. T. Ned.-Ind., 78, 2845 (Onderzoekingen over ratten-polyarthritis. 1 Ziekteverloop). 
Fabricant, J., AND Freundt, E. A. (1967) Ann. N.Y. Acad. Sci., 143, 50 (Importance of extension and standardization of laboratory tests for the identification and classification of mycoplasma).

Findlay, G. M., Mackenzie, R. D., MacCallum, F. O., AND Klieneberger, E. (1939) Lancet, 2, 7 (The aetiology of polyarthritis in the rat).

Golightly-Rowland, L., Cole, B. C., Ward, J. R., and Wiley, B. B. (1970) Infection and Immunity, 1, 538 (Effect of animal passage on arthritogenic and biological properties of Mycoplasma arthritidis).

JASMnN, G. (1957) Ann. rheum. Dis., 16, 365 (Experimental polyarthritis in rats injected with a tumour exudate).

- (1967) Rheumatology (Basel), 1, 107 (Experimental arthritis in rats. A comprehensive review with specific reference to mycoplasma).

KLIENEBerger, E. (1939) J. Hyg. (Camb.), 39, 260 (Studies on pleuropneumonia-like organisms: The L4 organism as the cause of Woglom's 'pyogenic virus').

MANChEe, R. J., AND TAYLOR-RoBINSON, D. (1968) J. gen. Microbiol., 50, 465 (Haemadsorption and haemagglutination by mycoplasmas).

Miles, A. A., AND MisRA, S. S. (1938) J. Hyg. (Camb.), 38, 732 (The estimation of the bactericidal power of the blood).

Parkes, M. W., and Wrigley, F. (1951) Ann. rheum. Dis., 10, 177 (Arthritis in rats produced by pleuropneumonia-like organisms).

Preston, W. S. (1942) J. infect. Dis., 70, 180 (Arthritis in rats caused by pleuropneumonia-like micro-organisms and the relationship of similar organisms to human rheumatism).

ScHürze, E. (1968) Zbl. Bakt., abteil. 1 (Orig.) 208, 301 (Mykoplasma-Modell-Infektionen bei kleinen Laboratoriumstieren).

TAYLOR-Robinson, D. (1967) Post-grad. med. J., 43, Suppl. [March] 'The Chemotherapy of Infections,' pp. 100-116 (Mycoplasmas of various hosts and their antibiotic sensitivities).

TrIPI, H. B., AND KuZELl, W. C. (1947) Stanford med. Bull., 5, 98 (Production of experimental polyarthritis by pleuropneumonia-like (L4) organisms in rats and preliminary results on protective effects of a gold product).

WARD, J. R., AND JoNES, R. S. (1962) Arthr. and Rheum., 5, 163 (The pathogenesis of mycoplasmal (PPLO) arthritis in rats). 